\title{
Profile of paritaprevir/ritonavir/ombitasvir plus dasabuvir in the treatment of chronic hepatitis $C$ virus genotype I infection
}

This article was published in the following Dove Press journal:

Drug Design, Development and Therapy

13 November 2015

Number of times this article has been viewed

\section{Michael A Smith \\ Alice Lim}

Department of Pharmacy Practice and Pharmacy Administration, Philadelphia College of Pharmacy, University of the Sciences, Philadelphia, PA, USA

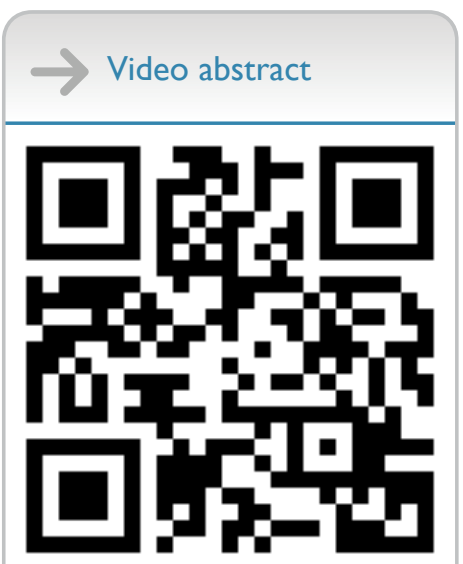

Point your SmartPhone at the code above. If you have a QR code reader the video abstract will appear. Or use: http://youtu.be/MI3PcLBhx3k

Correspondence: Michael A Smith Department of Pharmacy Practice and Pharmacy Administration, University of the Sciences, Philadelphia College of Pharmacy, 600 South 43rd Street, Philadelphia, PA 19104, USA

Tel +l 2155967246

Fax + I 2155968586

Email mic.smith@usciences.edu
Abstract: Over the last several years, many advances have been made in the treatment of chronic hepatitis $\mathrm{C}$ virus (HCV) infection with the development of direct-acting antivirals. Paritaprevir/ ritonavir/ombitasvir with dasabuvir (PrOD) is a novel combination of a nonstructural (NS) 3/4A protein inhibitor boosted by ritonavir, an NS5A protein inhibitor, and an NS5B nonnucleoside polymerase inhibitor. This review aims to discuss the pharmacology, efficacy, safety, drug interactions, and viral drug resistance of PrOD in the treatment of HCV genotype 1 infections. Phase I, II, and III human and animal studies that describe the pharmacology, pharmacokinetics, efficacy, and safety of PrOD for HCV were identified and included. Studies that evaluated patients without cirrhosis $(n=2,249)$ and with cirrhosis $(n=422)$ demonstrated that PrOD for 12 or 24 weeks was effective at achieving sustained virologic response rates $(>90 \%)$ in patients with genotype $1 \mathrm{a}$ or $1 \mathrm{~b} \mathrm{HCV}$ infection. Although indicated for the treatment of HCV genotype 1 infection, PrOD is also recommended for the treatment of $\mathrm{HCV}$ in patients coinfected with HIV. Additionally, promising data exist for the use of PrOD in liver-transplant recipients. The most common adverse drug events associated with PrOD included nausea, pruritus, insomnia, diarrhea, asthenia, dry skin, vomiting, and anemia. The high efficacy rates seen coupled with a favorable side effect profile seen with PrOD with or without ribavirin have led to its addition as a recommended treatment regimen for HCV genotype 1 infection.

Keywords: direct-acting antiviral, interferon-free, ribavirin-free

\section{Introduction}

The World Health Organization and the Centers for Disease Control and Prevention have estimated global and national rates of chronic hepatitis $\mathrm{C}$ virus (HCV) infection to be approximately 180 million and 4 million people, respectively. ${ }^{1,2}$ Given the large number of patients infected with $\mathrm{HCV}$, there has been great interest in drug development to improve on the sustained virologic response (SVR) rates of peginterferon (PegIFN)/ribavirin (RBV). In 2011, the first direct-acting antiviral (DAA) was approved and, since then, the field has grown so rapidly that guideline recommendations have been moved to a website (www.hcvguidelines.org). ${ }^{3}$ The landscape of DAA approval and use has evolved at such a rate that the first-generation DAAs (eg, telaprevir and boceprevir) are practically obsolete, giving way to new combinations of treatments.

The combination of paritaprevir (a nonstructural [NS] 3/4a protein inhibitor), ritonavir, ombitasvir (an NS5A protein inhibitor), and dasabuvir (an NS5B nonnucleoside polymerase inhibitor) with or without RBV has been approved to treat HCV genotype 1 infections. ${ }^{4}$ This combination, PrOD, is currently recommended as a first-line regimen for patients who are treatment-naïve with genotype 1a (with or without cirrhosis $+\mathrm{RBV}$ ), $1 \mathrm{~b}$ (with or without cirrhosis $+\mathrm{RBV}$ in cirrhosis), and 
4 (without dasabuvir $+\mathrm{RBV}$ ). It is also recommended for patients who have previously failed PegIFN/RBV with genotype 1a (with or without cirrhosis + RBV), 1b (with or without cirrhosis + RBV), and 4 (without dasabuvir + $\mathrm{RBV}){ }^{3}$ This review will focus on the use of PrOD to treat $\mathrm{HCV}$ genotype 1 infections.

\section{Clinical pharmacology}

Paritaprevir, previously known as ABT-450, inhibits the function of NS3/4A protease, which is an essential component of HCV viral replication. The half-maximal effective concentrations $\left(\mathrm{EC}_{50} \mathrm{~s}\right)$ and intracellular concentrations of paritaprevir needed for potent antiviral activity against HCV genotype $1 \mathrm{a}$ and $1 \mathrm{~b}$ were 1.0 and $0.21 \mathrm{nmol} / \mathrm{L}$ and 0.18 and $0.43 \mathrm{nM}$, respectively., 5 Wen combined with the cytochrome P-450 (CYP-450) 3A4 inhibitor ritonavir, which has no $\mathrm{HCV}$ inhibitory properties, the area under the curve (AUC) of paritaprevir was increased approximately 48-fold while peak concentrations increased approximately 28-fold. The addition of ritonavir also prolonged the elimination halflife of paritaprevir, allowing for once-daily dosing. ${ }^{5}$ After oral administration, paritaprevir/ritonavir reached maximal exposure, above a dose-proportional response, in approximately 4 hours. Paritaprevir has an absolute bioavailability of approximately $50 \%$, is highly protein bound, and has a moderate volume of distribution $(16.7 \mathrm{~L})$. Paritaprevir is metabolized by CYP3A4 and 3A5 and is mostly excreted in the feces (nearly 90\%).

Ombitasvir, previously known as ABT-267, is an inhibitor of NS5A, which is a phosphoprotein without enzymatic function but remains vital to HCV replicase. ${ }^{8,9}$ Its role in the HCV life cycle has been previously detailed in the journal Drug Design, Development and Therapy. ${ }^{10} \mathrm{The}^{\mathrm{EC}}{ }_{50}$ of ombitasvir in genotype $1 \mathrm{a}$ and $1 \mathrm{~b}$ replicons is 14 and $5 \mathrm{pmol} / \mathrm{L}$. The in vitro activity of ombitasvir has not been reported, given its lack of enzymatic function. ${ }^{9}$ As with paritaprevir, the time to maximal concentration is approximately 4 hours in a dose-proportional manner with an absolute bioavailability of $50 \%$. The drug is highly protein bound with a large volume of distribution (50 L) and undergoes amide hydrolysis followed by oxidative metabolism producing antiviral inactive metabolites. Ombitasvir is primarily excreted in the feces (90\%) with an elimination half-life of over 20 hours. ${ }^{4,11,12}$

Dasabuvir, previously known as ABT-333, is a nonnucleoside NS5B polymerase inhibitor that showed potent antiviral activity with $\mathrm{EC}_{50} \mathrm{~s}$ and intracellular concentrations of 7.7 and $1.8 \mathrm{nmol} / \mathrm{L}$ and 2.8 and $3.7 \mathrm{nM}$ to HCV genotype $1 \mathrm{a}$ and $1 \mathrm{~b}$, respectively. ${ }^{4,13,14}$ Dasabuvir and ombitasvir have similar absorption pharmacokinetics, with an absolute bioavailability of approximately $50 \%$ after oral administration. Dasabuvir is also highly protein bound with extensive distribution (396 L). It is metabolized to an active metabolite, M1, by CYP2C8. This metabolite has similar efficacy to that of dasabuvir. Nearly the entire dose (94\%) is eliminated in the feces with an elimination half-life of 6 hours. ${ }^{4,13,14}$

Given the large role of hepatic metabolism, the pharmacokinetics of PrOD in patients with hepatic impairment is important. In a Phase I, single-dose trial of healthy participants with varying degrees of hepatic impairment, the pharmacokinetics of PrOD were evaluated. ${ }^{15}$ The study showed that mild hepatic impairment (Child-Pugh class A) did not significantly affect the pharmacokinetic parameters assessed $\left(\mathrm{C}_{\max }, \mathrm{T}_{\max }, \mathrm{AUC}\right.$, half-life, clearance, and unbound fraction of drug). The authors defined comparable as a $\pm 30 \%$ difference from healthy controls. Drug exposure in mild hepatic impairment was within this range with the exception of ritonavir, which was decreased (34\%). In moderate hepatic impairment (Child-Pugh class B), drug exposure was within this range with the exception of paritaprevir, which was increased (62\%). Compared to the healthy controls, patients with severe hepatic impairment (Child-Pugh class C), drug exposure of paritaprevir was increased (920\%), ritonavir was within range, ombitasvir was decreased $(55 \%)$, and dasabuvir was increased (320\%). Elimination halflives were not particularly affected by hepatic impairment in mild and moderate disease; however, in severe disease, the half-lives of ritonavir and dasabuvir were significantly prolonged (approximately threefold). ${ }^{15}$ Based on this data, PrOD is contraindicated in patients with severe hepatic impairment and not recommended in moderate hepatic impairment.

No dosage adjustments are recommended in patients with any stage of renal dysfunction based on another Phase I pharmacokinetic study. Although the study showed changes in AUC in patients with creatinine clearances above $15 \mathrm{~mL} / \mathrm{min}$, elimination half-lives were not significantly different. ${ }^{4}$

\section{Clinical trials}

To date, there have been seven Phase III clinical trials evaluating the safety and efficacy of PrOD, with or without $\mathrm{RBV}$, for HCV genotype 1 infection. ${ }^{16-21}$ For the primary outcome, each trial evaluated SVR at 12 weeks after the end of treatment (SVR12) as compared to the historical SVR12 rates of telaprevir/PegIFN/RBV therapy. Virologic failure and virologic relapse were also assessed. Virologic failure during treatment was defined as an HCV RNA level of $25 \mathrm{IU} / \mathrm{mL}$ or more during treatment, increase in HCV RNA 
level of more than $1 \log _{10} \mathrm{IU} / \mathrm{mL}$ above nadir during treatment, or HCV RNA level of $25 \mathrm{IU} / \mathrm{mL}$ or more at any time during treatment in patients who received at least 6 weeks of treatment. Virologic relapse was defined as an HCV RNA level of $25 \mathrm{IU} / \mathrm{mL}$ or more after the end of completed treatment. All trials included patients aged 18-70 years (GIFT-I included patients aged 18-75 years) with HCV RNA levels $>10,000 \mathrm{IU} / \mathrm{mL}$ and who did not have coinfection with hepatitis B or HIV-1. In studies of noncirrhotic patients, absence of cirrhosis was confirmed either by liver biopsy (Metavir score of 3 or less or Ishak score of 4 or less), FibroTest score of $\leq 0.72$ and aspartate aminotransferaseto-platelet ratio index (APRI) of $\leq 2$, or FibroScan ${ }^{\circledR}$ result of $<9.6 \mathrm{kPa}(<12.6 \mathrm{kPa}$ in the GIFT-I study). Most of the studies were conducted in North America and Europe, ${ }^{16-19,21}$ and some studies included patients from Australia. ${ }^{16,17}$ One study was conducted in Japan. ${ }^{20}$ In each trial, treatment doses were paritaprevir $150 \mathrm{mg}$, ritonavir $100 \mathrm{mg}$, and ombitasvir $25 \mathrm{mg}$ given once daily as a co-formulated tablet, along with dasabuvir $250 \mathrm{mg}$ twice daily. If RBV was given, the dose was weight-based (1,000 mg daily if body weight $<75 \mathrm{~kg}$, $1,200 \mathrm{mg}$ daily if body weight was $\geq 75 \mathrm{~kg}$ ).

Historically, interleukin 28B (IL28B) non-CC genotype, black race, higher fibrosis scores, and higher baseline HCV RNA levels were associated with decreased response to HCV therapy, specifically with PegIFN/RBV therapy. Thus, each trial performed analyses of these characteristics to determine their influence on the efficacy of PrOD. The study characteristics and results are summarized in Table 1.

\section{Noncirrhotic patients}

SAPPHIRE-I was a randomized, double-blind, placebocontrolled trial that evaluated the use of PrOD plus RBV in treatment-naïve, noncirrhotic patients with either genotype la or $1 \mathrm{~b}$ infection. Six hundred and thirty-one patients were randomized in a 3:1 ratio to receive active treatment or placebo; $96.2 \%$ of patients in the active treatment arm achieved SVR12. Response rates by genotype were $95.3 \%$ in patients with genotype 1a infection and $98.0 \%$ in patients with genotype $1 \mathrm{~b}$ infection. Compared to the historical response rate with telaprevir/PegIFN/RBV therapy (SVR12 78\%), this regimen was found to be both noninferior and superior. The high SVR rates were unaffected by IL28B genotype, race, fibrosis score, and baseline HCV RNA level. However, elevated body mass index (BMI) was significantly associated with reduced SVR rates (odds ratio 0.89, $P=0.02$ ). Still, those with $\mathrm{BMI}>30 \mathrm{~kg} / \mathrm{m}^{2}$ experienced a high response rate of 91.5\%. Overall, the study demonstrated high SVR12 rates with a regimen of PrOD plus RBV. ${ }^{16}$
SAPPHIRE-II compared PrOD plus RBV versus placebo in genotype $1 \mathrm{a}$ and $1 \mathrm{~b}$ infection for those who previously failed PegIFN and RBV dual therapy. Three hundred and ninety-four patients were stratified by type of treatment failure and were randomized 3:1 to receive active treatment versus placebo for 12 weeks. Overall, the response rate was high at $96.3 \%$, which was superior compared to the rates seen historically with telaprevir/PegIFN/RBV (SVR12 65\%). Patients with genotype $1 \mathrm{a}$ and $1 \mathrm{~b}$ experienced similarly high response rates, at $96 \%$ and $96.7 \%$, respectively. SVR rates were $95.3 \%$ for those with prior relapse, $100 \%$ for those with prior partial response, and $95.2 \%$ for those with prior null response. Patient characteristics such as age, race, fibrosis score, HCV RNA level, and IL28B genotype did not impact SVR12 rates. No virologic failures occurred during treatment; however, seven patients $(2.4 \%)$ experienced treatment relapse. Six of these patients had a prior null response to dual therapy. Similarly to treatment-naïve patients, SAPPHIRE-II demonstrated that treatment-experienced patients also experienced excellent efficacy with PrOD plus RBV. ${ }^{17}$

While all patients in the SAPPHIRE trials received RBV along with PrOD, PEARL-II, -III, and -IV evaluated the necessity of RBV therapy in HCV genotype 1 infection without cirrhosis. ${ }^{18,19}$ In PEARL-III, 419 treatment-naïve patients with genotype $1 \mathrm{~b}$ infection were randomized to receive PrOD with or without RBV. Both groups did well, with $99.5 \%$ of patients with RBV achieving SVR12 and $99.0 \%$ of patients without RBV achieving SVR12. The two patients who did not achieve SVR in the RBV-free group were lost to follow-up. One patient taking the regimen with RBV experienced virologic failure during treatment. There were no treatment relapses. Given the very high response rates in each group, IL28B genotype status did not appear to affect treatment efficacy. ${ }^{18}$

PEARL-IV utilized the same study design as PEARL-III but in genotype 1a patients. Three hundred and five patients were randomized in a 1:2 ratio to receive PrOD with or without RBV and were stratified by IL28B genotype. Response rates were $97.0 \%$ in the RBV group compared to $90.2 \%$ without RBV. While both rates were noninferior and superior to historical rates found with telaprevir/PegIFN/ RBV (SVR12 72\%), the RBV-free regimen failed to meet noninferiority when compared to treatment with RBV (difference $-6.8 \%, 95 \%$ confidence interval: -12.0 to -1.5$)$. Virologic failures occurred more frequently in the RBV-free group compared to the RBV group (7.8\% versus $2.0 \%)$. These patients were all found to have resistant variants. Unlike the genotype $1 \mathrm{~b}$ patients in PEARL-III, IL28B genotype did have a statistically significant impact on response, with IL28B CC 


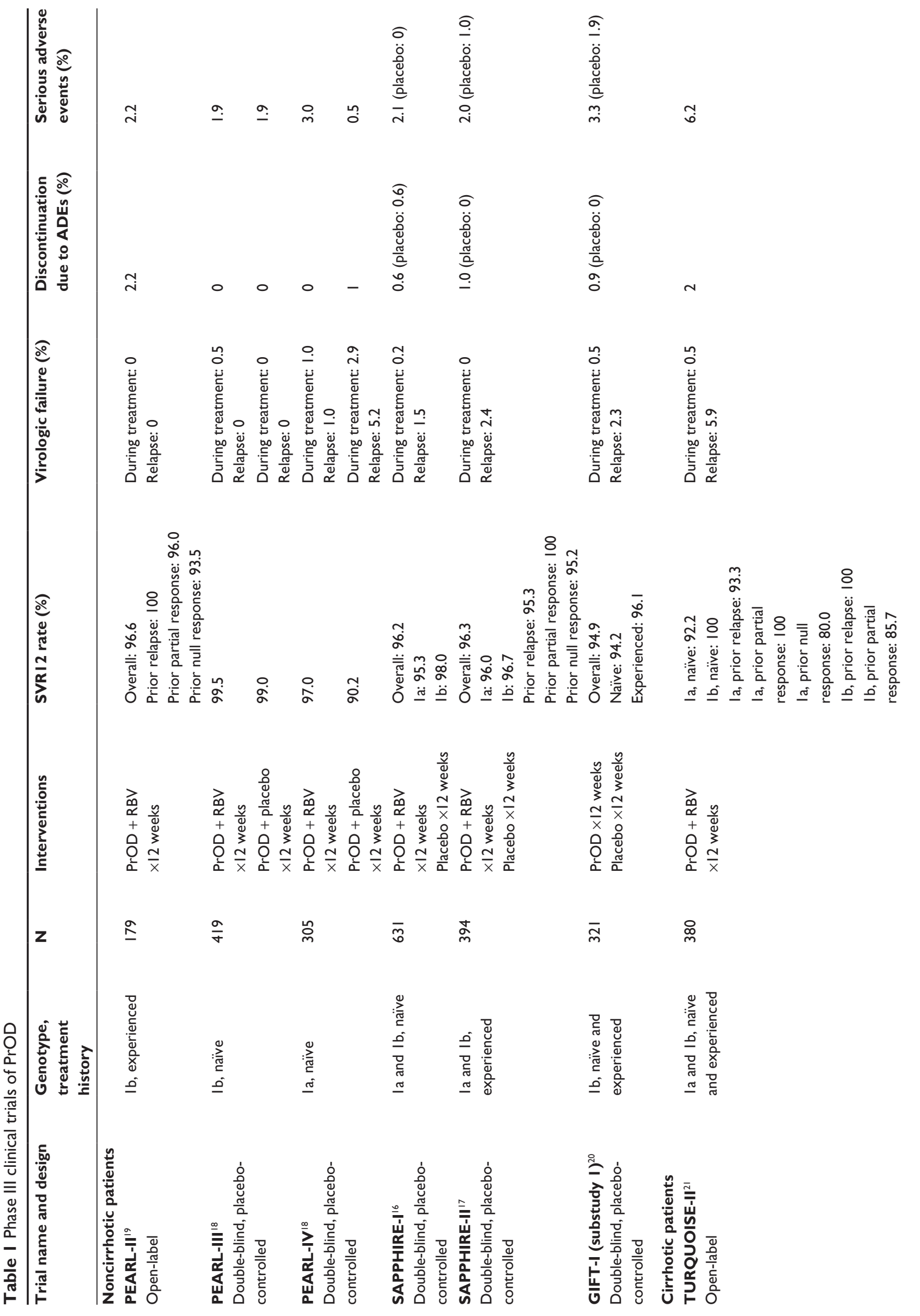




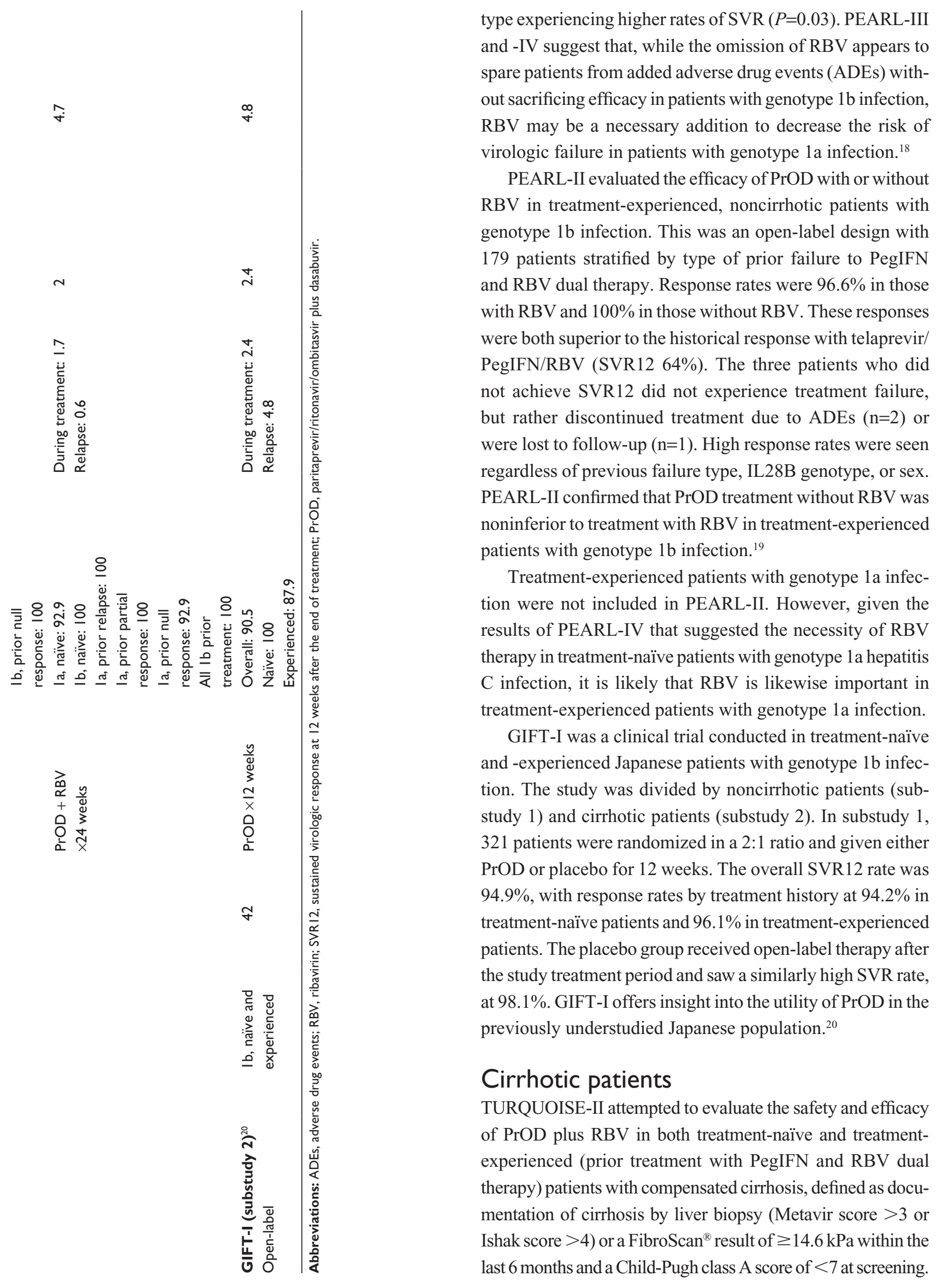

Drug Design, Development and Therapy 2015:9

submit your manuscript $\mid$ www.dovepress.com 
Patients with genotype $1 \mathrm{a}$ and $1 \mathrm{~b}$ infection were both included. The study excluded patients with hepatocellular carcinoma, current or past evidence of Child-Pugh score B or C, platelet count $<60,000 / \mathrm{m}^{3}$, serum albumin $<2.8 \mathrm{~g} / \mathrm{dL}$, total bilirubin $>3 \mathrm{mg} / \mathrm{dL}$, international normalized ratio $>2.3$, and serum alpha-fetoprotein level $>100 \mathrm{ng} / \mathrm{mL}$. Three hundred and eighty patients were randomized to receive open-label PrOD plus RBV for 12 or 24 weeks. Compared to the historical SVR rate of telaprevir/PegIFN/RBV of $47 \%$, both 12 weeks and 24 weeks were superior in efficacy, at $91.8 \%$ and $95.9 \%$, respectively. The difference in SVR rates between the two duration groups was not significant $(P=0.09)$; however, the difference was more pronounced in patients with genotype 1a infection who had a prior null response (12 weeks: 80\%, 24 weeks: $92.9 \%$ ). In treatment-naïve patients, the response rates for genotype $1 \mathrm{a}$ and $1 \mathrm{~b}$ infection were $92.2 \%-92.9 \%$ and $100 \%$, respectively. Response rates were unaffected by race, BMI, diabetes diagnosis, baseline HCV RNA level, platelet count, and albumin level. On the other hand, genotype 1a infection, former injection drug use, and prior null response were associated with lower SVR12 rates. Significantly more patients in the 12-week duration group experienced a relapse compared to the 24-week group. A majority of these patients had HCV genotype 1a infection and a prior null response, suggesting that longer durations of therapy are warranted in this population. ${ }^{21}$

In substudy 2 of GIFT-I, which included treatment-naïve and -experienced cirrhotic patients, 42 Japanese patients received open-label PrOD for 12 weeks. Cirrhosis was confirmed by liver biopsy (Metavir Score or New Inuyama score $>3$ or Ishak score $>4$ ), a FibroTest result of $\geq 0.73$ and APRI $>2$, FibroScan ${ }^{\circledR}$ score $\geq 14.6 \mathrm{kPa}$, or screening discriminant score $>0$. Patients must also have had a Child-Pugh score of $\leq 6$ at screening. A majority of patients were treatment-experienced (78.6\%). Overall, 90.5\% of patients reached SVR12, with treatment-naïve patients and treatment-experienced patients achieving response rates of $100 \%$ and $87.9 \%$, respectively. ${ }^{20}$

TURQUOISE-II studied the utility of PrOD with RBV in cirrhotic patients, while GIFT-I demonstrated high efficacy of PrOD without RBV in genotype $1 \mathrm{~b}$ patients with cirrhosis. Data from the TURQUOISE-III study confirmed the safety and efficacy of PrOD without RBV for 12 weeks in patients with genotype $1 \mathrm{~b}$ infection and compensated cirrhosis. All 60 patients achieved SVR12. ${ }^{22}$

All seven trials demonstrated superior efficacy compared to the previous standard therapy of a protease inhibitor with PegIFN/RBV in the treatment HCV genotype 1. These trials were instrumental in determining the most recent guidelines for HCV genotype 1 infection, and that treatment should be dictated by genotype, treatment history, and presence of cirrhosis. RBV may be omitted in treatment-naïve and -experienced patients with genotype $1 \mathrm{~b}$ infection with or without cirrhosis. On the other hand, RBV therapy is necessary in treatment-naïve and -experienced genotype 1a infection. In compensated cirrhosis, patients with genotype 1a infection require a 24-week duration of PrOD plus RBV, while patients with genotype $1 \mathrm{~b}$ infection require a 12 -week duration of PrOD without RBV regardless of treatment history. ${ }^{3}$

The strengths of these studies include their overall consistency in trial design, primary outcomes, and stratifications of characteristics historically shown to influence treatment efficacy. The placebo-controlled designs of SAPPHIRE-I, SAPPHIRE-II, and substudy 1 of GIFT-I allowed for an unobstructed view of the ADE profile of PrOD with or without RBV. ${ }^{16,17,20}$ Given the clear benefit of therapy over placebo, patients randomized to the placebo arms received open-label active treatment after the study period. However, several limitations must be considered. While the trials were conducted in multiple centers across different countries, they were widely Western populations with little representation of non-Caucasian races. ${ }^{16-19,21}$ GIFT-I and results from a Phase II study show promising results in the Japanese population, but results for other races and ethnicities remain to be clarified. ${ }^{20,23}$ These trials also excluded patients with hepatitis B or HIV-1 coinfection, decompensated cirrhosis, uncontrolled diabetes with hemoglobin A1c $>8.5 \%$, and creatinine clearance $<60 \mathrm{~mL} / \mathrm{min}$.

Notably, BMI and IL28B genotype status significantly impacted efficacy rates in SAPPHIRE-I and PEARL-IV, respectively. ${ }^{16,18}$ The PEARL studies excluded patients with BMI $>38 \mathrm{~kg} / \mathrm{m}^{2}$, and thus may not have had enough patients with elevated BMI levels to detect a difference in efficacy rates. ${ }^{18,19}$ PEARL-IV only included genotype 1a patients, therefore the influence of IL28B genotype on response rates may be limited to this population, since IL28B status did not appear to impact other studies that included both genotype $1 \mathrm{a}$ and $1 \mathrm{~b}$ infected patients. ${ }^{16-18,21}$ However, without further investigation, this has yet to be confirmed. Currently available trials also do not elucidate the utility of PrOD in the retreatment of patients who failed therapies other than PegIFN/RBV dual therapy and how this regimen compares to the other first-line recommended therapy of ledipasvir/sofosbuvir.

\section{Special populations}

Phase II clinical trial data are available for patients with $\mathrm{HCV}$ and HIV coinfection and HCV patients who have undergone liver transplantation. ${ }^{24-26} \mathrm{HCV} / \mathrm{HIV}$ coinfection 
is of particular clinical interest, as these patients not only experience greater risk for liver disease progression but have also experienced relatively low SVR rates with treatment. ${ }^{27}$ Complicating treatment further is the inherent risk of drug interactions with many HIV medications. TURQUOISE-I enrolled patients from the USA and Puerto Rico with HCV genotype 1 and HIV infection. It included patients who were treatment-naïve or treatment-experienced to $\mathrm{HCV}$ medications with or without cirrhosis, with HIV-1 RNA $<40$ copies $/ \mathrm{mL}$, and CD4+ T-cell count $\geq 200 / \mathrm{mm}^{3}$ or CD4+ T-cell percentage $\geq 14 \%$. Patients were stable on atazanavir or raltegravir plus two nucleos $(\mathrm{t})$ ide analog reverse transcriptase inhibitors for at least 8 weeks. Sixty-three patients received open-label PrOD with RBV for 12 or 24 weeks. SVR12 rates were $94 \%$ ( 29 of 31 patients) and 91\% (29 of 32 patients) for 12 and 24 weeks of active treatment, respectively. The difference between treatment groups was not significant. Of the five patients who did not achieve SVR, two patients had genotype 1a infection, compensated cirrhosis, and prior null response to PegIFN and RBV. Two patients were treatmentnaive with noncirrhotic genotype 1a infection. One patient withdrew consent. Three patients in the 12-week group and five patients in the 24-week group had an HIV-1 RNA level higher than 40 copies $/ \mathrm{mL}$ during treatment. Still, this was lower than the rate typically seen in HIV-1 monoinfection, and all achieved resuppression without a change in either antiviral regimen. No patients experienced an HIV-1 RNA level $>200$ copies $/ \mathrm{mL}$, suggesting there are minimal clinically relevant effects on each regimen caused by drug interactions. The most common ADEs were fatigue, insomnia, nausea, and headache. The only severe ADE deemed related to study treatment was insomnia. One patient taking atazanavir had a grade 4 elevation in total bilirubin which improved to grade 3 without the need for interruption in therapy. There were no discontinuations due to ADEs. These results demonstrate promising efficacy and safety of PrOD with RBV in HCV/HIV coinfected patients, although there are a significant number of drug interactions with PrOD and antiretroviral therapies. ${ }^{24}$

$\mathrm{HCV}$ infection is the leading cause of liver transplantation. Unfortunately, patients commonly have recurrence of infection, and consequently experience accelerated fibrosis and cirrhosis. In the open-label CORAL-1 trial, PrOD with RBV for 24 weeks was evaluated in liver-transplant recipients with no or mild fibrosis, defined by a Metavir score $\leq 2$ on liver biopsy at least 9 months posttransplant and within 6 months of screening. Patients were included if they received a liver transplant at least 12 months prior to screening due to chronic $\mathrm{HCV}$ infection, had no evidence of advanced fibrosis within 6 months of screening, and were on a stable regimen of tacrolimus or cyclosporine with or without glucocorticosteroids. Concomitant cyclosporine or tacrolimus doses were decreased due to the boosting effects of ritonavir therapy. A majority of the patients had genotype 1a infection and non-CC IL28B genotype and had been previously treated with PegIFN and RBV. Out of 34 patients enrolled, 33 achieved SVR12 and SVR24 (97\%). One patient with genotype 1a infection experienced a relapse and was found to have several resistance-associated variants. The most common ADEs were fatigue, headache, and cough. One patient achieved SVR12 despite discontinuing treatment after week 18 due to rash, memory impairment, and anxiety. Of note, RBV dosing was individualized and determined by the investigator due to the risk of hematologic toxicity in transplant recipients. A majority of patients received 600 or $800 \mathrm{mg}$ daily at initiation and by completion. Nineteen patients decreased RBV during treatment, mostly due to hemoglobin declines. Five patients who had initial RBV doses of 1,000 or $1,200 \mathrm{mg}$ daily required erythropoietin. ${ }^{25}$

Preliminary data from a Phase III study of genotype 1 patients with chronic kidney disease (stage 4 or 5) without cirrhosis or coinfection was reported in the Ruby-I trial. ${ }^{28}$ Thirteen genotype la patients were given PrOD plus RBV for 12 weeks while seven genotype $1 \mathrm{~b}$ patients were given PrOD without RBV for 12 weeks. The majority of patients were male (85\%), black (70\%), without fibrosis (F0-F1 50\%), and on dialysis (65\%). Virologic response was assessed at the end of treatment $(100 \%$ for $n=14)$, SVR4 $(100 \%$ for $n=10)$, and SVR12 (100\% for $n=2)$. The Ruby-I trial showed that the use of PrOD was safe and effective in patients with endstage renal disease, including those on dialysis. ${ }^{28}$

\section{Drug interactions}

Paritaprevir and ritonavir are mostly metabolized through the CYP3A system, while dasabuvir is mostly metabolized by CYP2C 8 and, to a lesser extent, by CYP3A4. Ombitasvir undergoes amide hydrolysis followed by oxidative metabolism. Paritaprevir is a substrate and inhibitor of organic anion transporting polypeptide (OATP) IB1/B3, P-glycoprotein (P-gp), and breast cancer resistance protein (BCRP). Ritonavir's primary role in the regimen is to inhibit CYP3A, but it also inhibits P-gp and BCRP. Dasabuvir is a P-gp and BCRP inhibitor. Ombitasvir, paritaprevir, ritonavir, and dasabuvir are all substrates of P-gp and BCRP., 429

Mechanism-based drug-drug interactions and interactions with commonly prescribed medications in the $\mathrm{HCV}$-infected 
population have been studied in a total of 228 subjects. ${ }^{29,30}$ Findings and recommendations are detailed in Table 2. ${ }^{29-32}$ Importantly, the presented information does not include every drug-drug interaction, and more interactions are likely to be revealed with future studies and Phase IV data.
Interactions specifically with HIV antiretroviral medications and immunosuppressants have been studied. In healthy volunteers, the AUC and $\mathrm{C}_{\max }$ of paritaprevir increased by $46 \%$ and $94 \%$ with atazanavir, and $119 \%$ and $216 \%$ with lopinavir, respectively. Meanwhile, trough concentrations

Table 2 PrOD drug-drug interactions and recommendations

\begin{tabular}{|c|c|c|}
\hline Drug class & Studied medications & Recommendation with PrOD regimen coadministration \\
\hline \multicolumn{3}{|l|}{ Contraindications } \\
\hline Alpha-I adrenergic antagonists & Alfuzosin & Contraindicated due to risk of hypotension \\
\hline Anticonvulsants & $\begin{array}{l}\text { Carbamazepine, phenobarbital, } \\
\text { phenytoin }\end{array}$ & Strong CYP3A4 inducers are contraindicated \\
\hline \multirow[t]{2}{*}{ Antihyperlipidemics } & Gemfibrozil & Strong CYP2C8 inhibitors are contraindicated \\
\hline & Lovastatin, simvastatin & Contraindicated due to risk of myopathy \\
\hline Antimycobacterials & Rifampin & Strong CYP3A4 inducers contraindicated \\
\hline Antipsychotics & Pimozide & Contraindicated due to risk of QT prolongation \\
\hline \multirow[t]{4}{*}{ Antiretrovirals } & Darunavir/ritonavir & Not recommended due to decreased darunavir concentrations \\
\hline & Efavirenz & Contraindicated due to liver enzyme elevations \\
\hline & Lopinavir/ritonavir & Not recommended due to increased paritaprevir concentrations \\
\hline & Rilpivirine & Not recommended due to risk of QT prolongation \\
\hline Anxiolytics & Oral midazolam, triazolam & $\begin{array}{l}\text { Contraindicated due to increased risk of serious side effects } \\
\text { including sedation and respiratory depression }\end{array}$ \\
\hline Ergot derivatives & $\begin{array}{l}\text { Ergotamine, dihydroergotamine, } \\
\text { ergonovine, methylergonovine }\end{array}$ & Contraindicated due to risk of ergot toxicity \\
\hline Herbal products & St John's wort & Strong CYP3A4 inducers contraindicated \\
\hline Long-acting beta-adrenergic agonists & Salmeterol & $\begin{array}{l}\text { Contraindicated due to risk of cardiovascular adverse effects such } \\
\text { as QT prolongation }\end{array}$ \\
\hline Oral contraceptives & Ethinyl estradiol-containing products & Contraindicated due to liver enzyme elevations \\
\hline Phosphodiesterase-5 inhibitors & $\begin{array}{l}\text { Sildenafil (for treatment of pulmonary } \\
\text { arterial hypertension) }\end{array}$ & $\begin{array}{l}\text { Contraindicated due to increased risk of sildenafil-associated } \\
\text { adverse effects }\end{array}$ \\
\hline \multicolumn{3}{|l|}{ Dose adjustments recommended } \\
\hline Angiotensin II receptor blockers & Valsartan, olmesartan, telmisartan & $\begin{array}{l}\text { Increased concentrations of OATPIB substrates; lower doses } \\
\text { recommended }\end{array}$ \\
\hline Antifungals & Ketoconazole & $\begin{array}{l}\text { Increased concentrations of CYP3A substrates; limit ketoconazole } \\
\text { and itraconazole to } \leq 200 \mathrm{mg} / \text { day } \\
\text { Lower doses for posaconazole } \\
\text { Voriconazole not recommended }\end{array}$ \\
\hline Antihyperlipidemics & Pravastatin, rosuvastatin & $\begin{array}{l}\text { Increased concentrations of OATPBI substrates } \\
\text { Maximum dose pravastatin } 40 \mathrm{mg} / \text { day } \\
\text { Maximum dose rosuvastatin } 10 \mathrm{mg} / \text { day } \\
\text { Lower doses of pitavastatin and fluvastatin }\end{array}$ \\
\hline Antiretrovirals & Atazanavir/ritonavir & Administer atazanavir (without ritonavir) in the morning \\
\hline Calcium channel blockers & Amlodipine & $\begin{array}{l}\text { Increased concentrations of CYP3A4 substrates } \\
\text { Reduce amlodipine by } 50 \% \\
\text { Lower doses for other calcium channel blockers and monitor } \\
\text { Avoid felodipine and nisoldipine }\end{array}$ \\
\hline \multirow[t]{2}{*}{ Immunosuppressants } & Cyclosporine & $\begin{array}{l}\text { Reduce cyclosporine dose to } 20 \% \text { of current dose } \\
\text { Subsequent dose modifications based on blood concentrations } \\
\text { Monitor renal function and side effects frequently }\end{array}$ \\
\hline & Tacrolimus & $\begin{array}{l}\text { Do not administer tacrolimus on day of PrOD initiation } \\
\text { Reduce tacrolimus based on blood concentrations } \\
\text { Typical dose is } 0.5 \mathrm{mg} \text { every } 7 \text { days } \\
\text { Monitor renal function and side effects frequently }\end{array}$ \\
\hline \multicolumn{3}{|c|}{ Caution warranted, therapeutic monitoring recommended } \\
\hline Antiarrhythmics & $\begin{array}{l}\text { Amiodarone, bepridil, disopyramide, } \\
\text { flecainide, lidocaine (systemic), } \\
\text { mexiletine, propafenone, quinidine }\end{array}$ & $\begin{array}{l}\text { Increased concentrations of antiarrhythmics } \\
\text { Therapeutic concentration monitoring recommended }\end{array}$ \\
\hline Antiretrovirals & Atazanavir/ritonavir & Administer atazanavir (without ritonavir) in the morning \\
\hline
\end{tabular}


Table 2 (Continued)

\begin{tabular}{|c|c|c|}
\hline Drug class & Studied medications & Recommendation with PrOD regimen coadministration \\
\hline Anxiolytics & Alprazolam & Consider a decrease in alprazolam dose based on clinical response \\
\hline Corticosteroids (inhaled/nasal) & Fluticasone & Reduced concentrations of cortisol \\
\hline Diuretics & Furosemide & $\begin{array}{l}\text { Consider alternative corticosteroids } \\
\text { Increased concentrations of furosemide }\end{array}$ \\
\hline Proton-pump inhibitors & Omeprazole & $\begin{array}{l}\text { Adjust dose based on patient response } \\
\text { Consider omeprazole dose increase if symptoms are uncontrolled } \\
\text { and avoid }>40 \mathrm{mg} / \text { day of omeprazole }\end{array}$ \\
\hline \multicolumn{3}{|c|}{ No clinically significant interactions } \\
\hline Antiaddictives & Buprenorphine, methadone, naloxone & No dose adjustments are required \\
\hline Antiarrhythmics & Digoxin & \\
\hline Anticoagulants & Warfarin & \\
\hline Antidepressants & Escitalopram, citalopram, duloxetine, & \\
\hline Antiretrovirals & $\begin{array}{l}\text { fluoxetine, paroxetine, desipramine } \\
\text { Emtricitabine/tenofovir disoproxil } \\
\text { fumarate, raltegravir }\end{array}$ & \\
\hline Oral contraceptives & Norethindrone-only products & \\
\hline Sleep aids & Zolpidem & \\
\hline
\end{tabular}

Notes: Information adapted from previously published tables with permission from the publisher. This article was published in J Hepatol, 63(I), Menon RM, et al., Drug-drug interaction profile of the all-oral anti-hepatitis C virus regimen of paritaprevir/ritonavir, ombitasvir, and dasabuvir, 20-29.29 Copyright @2015 Elsevier.

Abbreviation: PrOD, paritaprevir/ritonavir/ombitasvir with dasabuvir.

increased for atazanavir and lopinavir and decreased for darunavir. As a result, lopinavir and darunavir are not recommended for coadministration with PrOD. Efavirenz toxicity increased significantly with PrOD, and coadministration is contraindicated. Rilpivirine AUC, $\mathrm{C}_{\max }$, and $\mathrm{C}_{\min }$ increased by $225 \%, 155 \%$, and $262 \%$, respectively, and should not be given with PrOD due to increased risk of QT prolongation. In contrast, no interactions were found with emtricitabine, raltegravir, or tenofovir. Studies with dolutegravir and elvitegravir have not yet been conducted. ${ }^{26,31}$

The narrow therapeutic window of immunosuppressants makes posttransplant patients especially susceptible to toxicity or decreased efficacy from these drugs. Cyclosporine, tacrolimus, and sirolimus are CYP3A4 and P-gp substrates. Cyclosporine moderately inhibits CYP3A4 and P-gp. While cyclosporine was shown to increase the $\mathrm{AUC}$ and $\mathrm{C}_{\max }$ of paritaprevir and decrease the $\mathrm{C}_{\text {max }}$ of dasabuvir in 12 healthy volunteers, these changes were considered clinically insignificant. In 72 healthy individuals participating in a Phase I study, PrOD increased the AUC and half-life of cyclosporine and tacrolimus. ${ }^{31}$ Based on these findings, the CORAL-1 study adjusted the doses of cyclosporine and tacrolimus in liver-transplant recipients. Participants taking cyclosporine had their dose reduced to $20 \%$ of their current dose. ${ }^{25}$ Dose adjustments were made throughout the study based on trough concentration levels. Tacrolimus doses were reduced to $0.5 \mathrm{mg}$ every 7 days and adjusted throughout the study based on trough concentrations. Mycophenolate mofetil was permitted in the study and required no dose adjustments. Though sirolimus was not permitted in the study, it is known that ritonavir may increase concentrations of sirolimus, thus warranting therapeutic drug monitoring. Ritonavir also has the potential to increase prednisolone, therefore doses of prednisolone (and prednisone) did not exceed $5 \mathrm{mg}$ daily in CORAL-1. ${ }^{25,26,31}$

\section{Safety}

The most common ADEs associated with PrOD treatment are nausea, pruritus, insomnia, diarrhea, asthenia, dry skin, vomiting, and anemia. The majority of patients treated in clinical trials experienced at least one ADE without the use of RBV (67\%-82\%); however, the use of RBV increases the risk of experiencing an ADE (79\%-97\%). Patients treated with RBV are more likely to suffer from fatigue, nausea, pruritus/rash, insomnia $(P \leq 0.08)$, increased bilirubin, exertional dyspnea, anemia, dry skin, and cough $(P<0.02$, except where noted). Duration of treatment also affected rates of ADEs, with those being treated for longer more likely to suffer from fatigue, dyspnea, back pain, memory impairment, and upper respiratory tract infections. Presence or absence of cirrhosis had no bearing on the rate of ADEs. Serious ADEs and therapy discontinuations were reported in $0 \%-3 \%$ and $2.2 \%$ of patients treated with PrOD plus RBV and $0 \%-6.2 \%$ and $2.3 \%$ of patients treated with PrOD, respectively. Similar rates were seen in treatment-experienced patients and patients coinfected with HIV. ${ }^{16-25}$

\section{Viral drug resistance}

During HCV replication, RNA-dependent RNA polymerase lacks the editing function to remove errors in base pairs, resulting in amino acid substitutions in $\mathrm{HCV}$ viral proteins. . $^{32,33}$ Coupled with high virion production, this potentiates a vastly 
heterogeneous viral population. As anti-HCV treatments work to eliminate wild-type $\mathrm{HCV}$, resistant variants survive and reproduce to eventually overtake the viral population, thus inciting virologic breakthrough and resistance to treatment. ${ }^{34-36}$ Mutations can develop in all three viral protein targets of PrOD, including NS3/4A, NS5A, and NS5B. The rate and type of resistance differs between genotype $1 \mathrm{a}$ and $1 \mathrm{~b} .{ }^{37}$ Given the lack of data on long-term effects of resistant variants, it remains to be determined whether resistance persists long enough to impact retreatment, and whether baseline resistance testing is valuable in informing treatment decisions.

\section{Paritaprevir}

In an in vitro study, HCV genotype $1 \mathrm{a}$ and $1 \mathrm{~b}$ viral colonies were exposed to paritaprevir at concentrations ten-, 100-, and 500 -fold greater than the $\mathrm{EC}_{50}$. In genotype $1 \mathrm{a}$, no colonies survived at concentrations 100 - or 500 -fold greater. The surviving colonies contained NS3 substitutions at R155K and $\mathrm{D} 168 \mathrm{E} / \mathrm{N}$. R155K almost universally results in resistance to HCV NS3/4A protease inhibitors, therefore the risk of crossresistance is high. In genotype $1 \mathrm{~b}$, no colonies survived at 500 -fold greater than $\mathrm{EC}_{50}$. The prevailing resistant variants observed were A156T and D168H/V/Y. In both genotypes, D168Y confers the highest level of resistance at $>200$-fold resistance. $^{5}$

\section{Ombitasvir}

After in vitro exposure to ombitasvir at ten-, 100-, or 1,000fold greater than the $\mathrm{EC}_{50}$, the predominant variants selected in genotype 1a were M28T/V, Q30R, and Y93C/H. When these resistant colonies were expanded, $\mathrm{M} 28 \mathrm{~V}$ resulted in 58-fold resistance, while M28T, Q30R, and Y93C/H resulted in $>800$-fold resistance. In vivo analysis of ombitasvir monotherapy in treatment-naïve genotype 1a infection led to resistant substitutions at amino acid positions M28, Q30, and Y93. None of the 12 patients had resistant variants detected at baseline. In genotype $1 \mathrm{~b}, \mathrm{Y} 93 \mathrm{H}$ was the most prevalent surviving variant, resulting in 77-fold resistance. Similar to other NS5A inhibitors, ombitasvir demonstrates a low genetic barrier to resistance and requires the coadministration of other agents to minimize the development of resistance. ${ }^{12}$

\section{Dasabuvir}

In one in vitro study, HCV colonies were exposed to dasabuvir at levels ten- or 100- fold greater than the $\mathrm{EC}_{50}$. The predominant surviving colony of $\mathrm{HCV}$ genotype 1a at concentrations tenfold greater was S556G (43\%). At concentrations 100-fold greater, C316Y, Y448C, C451R, and S556G were selected. Variants A395G, M414T, N444K, S556G/N, and $\mathrm{S} 565 \mathrm{~F}$ resulted in ten- to 32-fold resistance to dasabuvir, while $\mathrm{C} 316 \mathrm{Y}$ and $\mathrm{Y} 448 \mathrm{C} / \mathrm{H}$ resulted in $>940$-fold resistance. In genotype $1 \mathrm{~b}$ colonies, the predominant variants selected after exposure to dasabuvir at tenfold higher than $\mathrm{EC}_{50}$ were C316Y (33\%) and M414T (25\%). At concentrations 100fold greater, all 12 surviving colonies selected for $\mathrm{C} 316 \mathrm{Y}$. Again, C316Y substitution conferred the highest level of resistance, at 1,569-fold. S368T, N411S, M414T, and A553V produced 47- to 139-fold resistance. Additionally, C316Y, M414T, Y448H, and S556G variants were found to have the highest replication efficiency rate, further compounding the resistance rate against dasabuvir. ${ }^{13}$

Clinical trial data report the emergence of virologic resistance in patients receiving PrOD treatment who either failed therapy during treatment or experienced relapse. In patients with genotype $1 \mathrm{a}$ infection who failed treatment, the most frequently observed amino acid variants in genotype 1a infection were D168A/V/Y in NS3, M28T and Q30R in NS5A, and M414T and S556G in NS5B. ${ }^{16-18,21,38}$ The most frequently observed amino acid variants in patients with genotype $1 \mathrm{~b}$ infection who failed therapy were $\mathrm{Y} 56 \mathrm{H}$ and D168V in NS3, Y93H in NS5A, and S556G in NS5B. ${ }^{16-18,21,38}$

\section{Conclusion}

PrOD has been shown to be effective for the treatment of genotype $1 \mathrm{a}$ and $1 \mathrm{~b}$ chronic $\mathrm{HCV}$ infection in treatmentnaïve and treatment-experienced patients with and without cirrhosis. The addition of RBV to this regimen is still required in any patient with genotype 1a and in cirrhotic patients with genotype $1 \mathrm{~b}$ infections, which, along with its higher pill burden, may limit its use in comparison to other available agents. There is also evidence to support the use of PrOD in the treatment of special populations, including $\mathrm{HCV} / \mathrm{HIV}$ coinfection, post-liver-transplant HCV genotype 1 infections, and those with renal impairment. PrOD has an advantage over other antivirals on the market for patients with end-stage renal disease given the results of the Ruby-I study; however, its use in coinfection may be limited by the drugdrug interaction potential with antiretrovirals, and it should not be used in decompensated liver disease or in patients who previously failed a protease inhibitor. Clinical trial data have also shown PrOD to have a favorable ADE profile compared to historical regimens, with a higher risk of adverse events if used along with RBV. More clinical data are still needed to elucidate its use in those who failed prior therapies other than pegIFN/RBV, additional drug interactions, the impact of resistance on retreatment, and the utility of baseline resistance testing. Given the regimen's high efficacy and relatively mild side effect profile, PrOD with or without RBV is currently 
considered one of several first-line DAA regimens for the treatment of HCV genotype 1 infection.

\section{Disclosure}

The authors report no conflicts of interest in this work.

\section{References}

1. World Health Organization. Guidelines for the Screening, Care and Treatment of Persons with Hepatitis CInfection. Geneva: World Health Organization; 2014.

2. Smith BD, Morgan RL, Beckett GA, et al; Centers for Disease Control and Prevention. Recommendations for the identification of chronic hepatitis C virus infection among persons born during 1945-1965. MMWR Recomm Rep. 2012;61(RR-4):1-32.

3. Hepatitis $C$ Guidance: Recommendations for Testing, Managing, and Treating Hepatitis C [webpage on the Internet]. American Association for the Study of Liver Diseases (AASLD), Infectious Diseases Society of America (IDSA). Available from: http://www.hcvguidelines.org/. Accessed September 10, 2015.

4. Viekira Pak (ombitasvir, paritaprevir, and ritonavir tablets; dasabuvir tablets) copackaged for oral use [prescribing information]. North Chicago: AbbVie Inc; 2015.

5. Pilot-Matias $\mathrm{T}$, Tripathi $\mathrm{R}$, Cohen $\mathrm{D}$, et al. In vitro and in vivo antiviral activity and resistance profile of the hepatitis $\mathrm{C}$ virus NS3/4A protease inhibitor ABT-450. Antimicrob Agents Chemother. 2015;59(2): 988-997.

6. Gentile I, Borgia F, Buonomo AR, Zappulo E, Castaldo G, Borgia G. ABT-450: a novel protease inhibitor for the treatment of hepatitis $C$ virus infection. Curr Med Chem. 2014;21(28):3261-3270.

7. Badri P, Dutta S, Coakley E, et al. Pharmacokinetics and dose recommendations for cyclosporine and tacrolimus when coadministered with ABT-450, ombitasvir, and dasabuvir. Am J Transplant. 2015;15(5): 1313-1322.

8. Fridell RA, Qiu D, Valera L, Wang C, Rose RE, Gao M. Distinct functions of NS5A in hepatitis C virus RNA replication uncovered by studies with the NS5A inhibitor BMS-790052. J Virol. 2011; 85(14):7312-7320.

9. DeGoey DA, Randolph JT, Liu D, et al. Discovery of ABT-267, a pan-genotypic inhibitor of HCV NS5A. J Med Chem. 2014;57(5): 2047-2057.

10. Lee C. Daclatasvir: potential role in hepatitis C. Drug Des Devel Ther. 2013;7:1223-1233.

11. Gentile I, Buonomo AR, Borgia G. Ombitasvir: a potent pan-genotypic inhibitor of NS5A for the treatment of hepatitis C virus infection. Expert Rev Anti Infect Ther. 2014;12(9):1033-1043.

12. Krishnan P, Beyer J, Mistry N, et al. In vitro and in vivo antiviral activity and resistance profile of ombitasvir, an inhibitor of hepatitis $\mathrm{C}$ virus NS5A. Antimicrob Agents Chemother. 2015;59(2):979-987.

13. Kati W, Koev G, Irvin M, et al. In vitro activity and resistance profile of dasabuvir, a nonnucleoside hepatitis $\mathrm{C}$ virus polymerase inhibitor. Antimicrob Agents Chemother. 2015;59(3):1505-1511.

14. Gentile I, Buonomo AR, Borgia G. Dasabuvir: a non-nucleoside inhibitor of NS5B for the treatment of hepatitis C virus infection. Rev Recent Clin Trials. 2014;9(2):115-123.

15. Khatri A, Menon R, Marbury TC, et al. Pharmacokinetics and safety of coadministered paritaprevir plus ritonavir (paritaprevir/r), ombitasvir, and dasabuvir in hepatic impairment. J Hepatol. Epub 2015 Jun 10.

16. Feld JJ, Kowdley KV, Coakley E, et al. Treatment of HCV with ABT450/r-ombitasvir and dasabuvir with ribavirin. N Engl J Med. 2014; 370(17):1594-1603.

17. Zeuzem S, Jacobson IM, Baykal T, et al. Retreatment of HCV with ABT450/r-ombitasvir and dasabuvir with ribavirin. N Engl J Med. 2014; 370(17):1604-1614.
18. Ferenci P, Bernstein D, Lalezari J, et al; PEARL-III Study; PEARL-IV Study. ABT-450/r-ombitasvir and dasabuvir with or without ribavirin for HCV. N Engl J Med. 2014;370(21):1983-1992.

19. Andreone P, Colombo MG, Enejosa JV, et al. ABT-450, ritonavir, ombitasvir, and dasabuvir achieves $97 \%$ and $100 \%$ sustained virologic response with or without ribavirin in treatment-experienced patients with HCV genotype 1b infection. Gastroenterology. 2014; 147(2):359-365.e1.

20. Kumada H, Chayama K, Rodrigues L Jr, et al. Randomized phase 3 trial of ombitasvir/paritaprevir/ritonavir for hepatitis $\mathrm{C}$ virus genotype 1b-infected Japanese patients with or without cirrhosis. Hepatology. Epub 2015 Jul 3.

21. Poordad F, Hezode C, Trinh R, et al. ABT-450/r-ombitasvir and dasabuvir with ribavirin for hepatitis $\mathrm{C}$ with cirrhosis. $N$ Engl $J$ Med. 2014;370(21):1973-1982.

22. Feld JJ, Moreno C, Trinh R, et al. Turquoise-III: safety and efficacy of 12-week ribavirin-free treatment for patients with HCV genotype $1 \mathrm{~b}$ and cirrhosis. [Abstract P226.] 15th Annual International Symposium on Viral Hepatitis and Liver Disease. June 26-28, 2015; Berlin, Germany.

23. Chayama K, Notsumata K, Kurosaki M, et al. Randomized trial of interferon- and ribavirin-free ombitasvir/paritaprevir/ritonavir in treatment-experienced hepatitis C virus-infected patients. Hepatology. 2015;61(5):1523-1532.

24. Sulkowski MS, Eron JJ, Wyles D, et al. Ombitasvir, paritaprevir co-dosed with ritonavir, dasabuvir, and ribavirin for hepatitis $\mathrm{C}$ in patients co-infected with HIV-1: a randomized trial. JAMA. 2015;313(12):1223-1231.

25. Kwo PY, Mantry PS, Coakley E, et al. An interferon-free antiviral regimen for $\mathrm{HCV}$ after liver transplantation. $N$ Engl $J$ Med. 2014;371(25):2375-2382.

26. Toussaint-Miller KA, Andres J. Treatment considerations for unique patient populations with $\mathrm{HCV}$ genotype 1 infection. Ann Pharmacother. 2015;49(9):1015-1030.

27. Graham CS, Baden LR, Yu E, et al. Influence of human immunodeficiency virus infection on the course of hepatitis $\mathrm{C}$ virus infection: a meta-analysis. Clin Infect Dis. 2001;33(4):562-569.

28. Pockros PJ, Reddy KR, Mantry PS, et al. L01 : safety of ombitasvir/ paritaprevir/ritonavir plus dasabuvir for treating HCV GT1 infection in patients with severe renal impairment or end-stage renal disease: the Ruby-I study. J Hepatol. 2015;62:S257-S261.

29. Menon RM, Badri PS, Wang T, et al. Drug-drug interaction profile of the all-oral anti-hepatitis $\mathrm{C}$ virus regimen of paritaprevir/ritonavir, ombitasvir, and dasabuvir. J Hepatol. 2015;63(1):20-29.

30. Lalezari J, Sullivan JG, Varunok P, et al. Ombitasvir/paritaprevir/r and dasabuvir plus ribavirin in HCV genotype 1-infected patients on methadone or buprenorphine. J Hepatol. 2015;63(2):364-369.

31. Burgess S, Partovi N, Yoshida EM, Erb SR, Azalgara VM, Hussaini T. Drug interactions with direct-acting antivirals for hepatitis C: implications for HIV and transplant patients. Ann Pharmacother 2015;49(6):674-687.

32. Soriano V, Labarga P, Barreiro P, et al. Drug interactions with new hepatitis C oral drugs. Expert Opin Drug Metab Toxicol. 2015;11(3): 333-341.

33. Simmonds P. Genetic diversity and evolution of hepatitis C virus -15 years on. J Gen Virol. 2004;85(Pt 11):3173-3188.

34. Rong L, Dahari H, Ribeiro RM, Perelson AS. Rapid emergence of protease inhibitor resistance in hepatitis C virus. Sci Transl Med. 2010; 2(30):30ra32.

35. Halfon $\mathrm{P}$, Locarnini $\mathrm{S}$. Hepatitis $\mathrm{C}$ virus resistance to protease inhibitors. J Hepatol. 2011;55(1):192-206.

36. Kuntzen T, Timm J, Berical A, et al. Naturally occurring dominant resistance mutations to hepatitis $\mathrm{C}$ virus protease and polymerase inhibitors in treatment-naïve patients. Hepatology. 2008;48(6):1769-1778.

37. Wyles DL, Gutierrez JA. Importance of HCV genotype 1 subtypes for drug resistance and response to therapy. $J$ Viral Hepat. 2014;21(4):229-240.

38. Lontok E, Harrington $\mathrm{P}$, Howe A, et al. Hepatitis $\mathrm{C}$ virus drug resistanceassociated substitutions: state of the art summary. Hepatology. Epub 2015 Jun 10 


\section{Publish your work in this journal}

Drug Design, Development and Therapy is an international, peerreviewed open-access journal that spans the spectrum of drug design and development through to clinical applications. Clinical outcomes, patient safety, and programs for the development and effective, safe, and sustained use of medicines are a feature of the journal, which

has also been accepted for indexing on PubMed Central. The manuscript management system is completely online and includes a very quick and fair peer-review system, which is all easy to use. Visit http://www.dovepress.com/testimonials.php to read real quotes from published authors.

Submit your manuscript here: http://www.dovepress.com/drug-design-development-and-therapy-journal 